This item was submitted to Loughborough's Research Repository by the author.

Items in Figshare are protected by copyright, with all rights reserved, unless otherwise indicated.

\title{
Work demands, social support, and job satisfaction in eating disorder inpatient settings: A qualitative study
}

\section{PLEASE CITE THE PUBLISHED VERSION}

http://dx.doi.org/10.1111/inm.12014

\section{PUBLISHER}

Wiley-Blackwell (@ The Authors; International Journal of Mental Health Nursing; @ Australian College of Mental Health Nurses Inc.)

\section{VERSION}

AM (Accepted Manuscript)

\section{PUBLISHER STATEMENT}

This work is made available according to the conditions of the Creative Commons Attribution-NonCommercialNoDerivatives 4.0 International (CC BY-NC-ND 4.0) licence. Full details of this licence are available at: https://creativecommons.org/licenses/by-nc-nd/4.0/

\section{LICENCE}

CC BY-NC-ND 4.0

\section{REPOSITORY RECORD}

Davey, Amanda, Jon Arcelus, and Fehmidah Munir. 2019. "Work Demands, Social Support, and Job Satisfaction in Eating Disorder Inpatient Settings: A Qualitative Study". figshare. https://hdl.handle.net/2134/17203. 
Title: Work demands, social support and job satisfaction in eating disorders inpatient settings:

\section{A qualitative study}

Running title: Work demands in eating disorders staff

\section{Accepted Version}

\section{Amanda Davey, 1 Jon Arcelus ${ }_{1}$ and Fehmidah Munir 2}

${ }_{1}$ Loughborough University Centre for Research into Eating Disorders (LUCRED), and ${ }_{2}$ Centre for Global Health and Human Development, School of Sport, Exercise and Health Sciences, Loughborough University, Loughborough, UK 


\section{Abstract}

This qualitative study aimed to investigate work demands experienced by healthcare workers in an adult eating disorders inpatient service. It also aimed to investigate the use of social support and job satisfaction in this setting. Twelve healthcare workers from an eating disorders inpatient ward, including nurses, healthcare support workers and occupational therapists, participated in semi-structured interviews. Interviews were transcribed verbatim and analysed using thematic analysis. A number of work demands were discussed relating to therapeutic care, physical care and organisational demands. Most participants discussed social support at work as being highly valuable formally and informally, whereas external support was viewed as less important. Despite the challenges of caring for eating disordered patients, the majority of participants reported good patient-related job satisfaction but poor job satisfaction in relation to organisational factors. Eating disorders inpatient care is complex and demanding, necessitating effective teamwork, communication and support systems among healthcare workers. Interventions should be developed to target barriers to care, including time constraints, administrative workload and insufficient allocation of staff.

Key words: eating disorders, job satisfaction, social support, work demands 


\section{Introduction}

It is widely recognised that the caring professions are subject to high levels of occupational demands (Hegney et al., 2006). Healthcare workers are in close contact with patients, providing 'round the clock' care; they are the first to notice changes in patient health and therefore can most easily assist their needs and address problems (Morrison et al., 1997; Dunham-Taylor, 2000; Greco et al., 2006). Caring work often involves shift-work and irregular hours; complex decision making; and working both in teams and individually with patients (Niedhammer et al., 1994). Moreover, delivering the best possible care can be compromised by a lack of resources, particularly 'people resources' and funding (Prosser et al., 1997; Reid et al., 2010), which then creates greater job strain among healthcare workers. Prosser et al. (1997) found that clinical staff reported organisational factors, such as insufficient staffing, as significantly greater sources of stress compared to patient factors, such as feelings of hopelessness patients project onto staff. The complex ethical climate (Ulrich et al., 2007) and limited autonomy in clinical decision making (Traynor et al., 2010) also contribute to job strain. When comparing work locations in the context of mental health care for older adults, McCrae et al. (2007) found that ward-based staff experienced lower levels of work pressure compared to community mental health workers, suggesting that shared responsibilities and decision making as a team can alleviate work pressure.

Most research on work demands among healthcare workers assume that findings are generalisable across all areas of caring work. This may ignore key differences in the experiences of healthcare workers that are specific to their work context. One area that has received insufficient attention in the literature is eating disorders. Caring for patients with eating disorders is highly demanding (Kaplan \& Garfinkel, 1999) as the nature of the disorder

and complex needs of service users require intensive, multifaceted treatment. Therefore while it is useful to understand work demands typical of caring work, it is also important to explore work demands specific to working in eating disorders. 
Healthcare work in inpatient eating disorders units can be challenging and intensive (Snell et al., 2010). In some respects, it is remarkably different to caring for patients with other mental illnesses. Eating disorders patients, in particular those with anorexia nervosa, tend to present with denial and resistance to change (Vitousek, Watson \& Wilson, 1998); severe physical complications as a result of their disorder (Sharp \& Freeman, 1993); and are known to have the highest rate of mortality of any psychiatric disorder (Arcelus, Mitchell, Wales \& Nielsen, 2011). Inpatient units often treat the severest of cases and consequently staff must be vigilant for physical changes (Bhadoria et al., 2010), self-injurious behaviour (Paul et al., 2002) and suicide ideation (Fedorowicz et al., 2007), as well as providing a high level of care. According to Wright (2010), many healthcare workers in eating disorders report feeling overwhelmed, which, considering the characteristics of these patients, may be due to unique patient orientated work demands.

One particular challenge is developing therapeutic relationships with patients (Snell et al., 2010; Wright, 2010). It is common for eating disordered patients, particularly those with anorexia nervosa, to feel ambivalence about their illness and consequently towards treatment (Vitousek, Watson \& Wilson, 1998; Reid et al., 2010) making it difficult to set mutual goals (Wright, 2010). However, not enough is known about the work demands experienced by healthcare workers in eating disorders and whether some of the factors associated with buffering job stain, such as support, are available to them. The little research there is on healthcare workers in eating disorders reports the negative outcomes of work demands; little is known how healthcare workers derive their job satisfaction.

Therefore the aims of this study were to qualitatively explore the types of work demands experienced by healthcare workers in eating disorders; and how these work demands impact on healthcare workers' use of social support and feelings of job satisfaction. Qualitatively exploring participant's own understandings and realities, and the themes they collectively produce has been recognised as particularly useful in research in care work (McCann \& Clarke, 2003). 


\section{Methods and Materials}

The study was approved by the National Health Service Research Ethics Committee. Twenty-five staff members working in a UK specialist adult eating disorders service inpatient ward were invited to take part by the researcher. Inclusion criteria were: a minimum of three months' work experience in eating disorders services and employment as a nurse, healthcare support worker (HCSW) or occupational therapist (OT). All those who responded were eligible for the study and subsequently interviewed $(\mathrm{N}=12)$. No participants dropped out and all gave fully informed written consent. Of the twelve healthcare workers recruited for the study, seven were nurses, three were healthcare support workers, and two were occupational therapists. The majority of participants worked full time, with only four working part time, including regular part time hours and bank shifts. The age of participants ranged from 21 to 51 years (mean 38.42, SD 8.66) and only two participants were male. All participants identified their ethnicity as White British. Experience working in eating disorders ranged from less than one year to 16 years (mean 5.92, SD 5.11) and experience working in other areas of mental health ranged from zero to 20 years (mean 6.5, SD 6.26) (table 1).

\section{Please insert table 1 around here}

A qualitative design was chosen to explore the work experiences of eating disorders healthcare workers, given the lack of present research in this area. Semi-structured interviews were used to collect rich, in-depth data. An extensive literature review was used to structure and formulate the interview schedule. Interview questions were further developed by the researcher's clinical experience of working with eating disordered inpatients. The interview schedule was piloted and modified accordingly. Participants attended a face-to-face semistructured interview led by the researcher at the site of the eating disorder service. Interviews were audio-recorded and transcribed with the participants' permission. Due to the explorative 
nature of the study, data analysis followed principles of thematic analysis (Braun \& Clarke, 2006). This involved a six phase process: familiarising with data, generating initial codes, searching for themes, reviewing themes, defining and naming themes, and producing the report. Firstly the lead author (AD) systematically reviewed the transcripts. Each transcript was read three times and initial themes were noted each time, by hand. These were split into data units (sub-themes) and clustered. Higher order themes (umbrella term) which emerged during the initial stages of analysis were allocated to each cluster to represent the set of subthemes. The themes were discussed and reviewed between all authors to ensure consistency. Extracts corresponding with appropriate themes were taken from each transcript which enabled the authors to report quotes that reflected the overall accounts reported by participants.

\section{Results}

Three higher order themes were identified: work demands, social support and job satisfaction, each with a number of sub-themes (see Table 2). The findings are described below.

Please insert table 2 around here

\section{Work Demands}

Therapeutic care

One of the most important aspects of a healthcare worker's role was building therapeutic relationships with patients. This was essential in engaging patients with their treatment, collaborating on patients' care plans and helping them through difficulties. However a major therapeutic challenge for participants was managing patients' ambivalence towards treatment and in following through with interventions:

[ppt 9, OT] The hardest challenge is non-compliance. If they're saying they're not going 
to do it that's fine because it's straightforward, it's when they say they will do it, they want to do it but they're secretly kind of sabotaging it as they go along...it's very difficult to work with people that...they want to get better but without letting go of their eating disorder so that kind of mindset is very difficult to work with.

Within the therapeutic relationship, several participants reported a complex dynamic whereby patients had very specific perceptions of staff roles. These participants felt that patients tended to see them in either a mother or friend role and this was usually related to the age of the patient and member of staff. For some participants this presented a difficulty in establishing a professional relationship with patients whereas others saw it as a way to work on patients' interpersonal difficulties:

[ppt 11, nurse] I'm aware being an older person that I may fall into that 'mummy' category and maybe sometimes I get some transference to do with their relationship with their mums... It has its uses, definitely, because sometimes they work through things that are associated with the mum through me.

Managing patients' expectations was also a challenge for some participants as they perceived them often to be unrealistic in terms of one-to-one time with staff, opportunities for non-ward-based activities, the general recovery process, and delivery of care. One participant associated this with the perfectionistic personality traits of eating disordered patients:

[ppt 7, nurse] They have very high unrealistic expectations... because of their personality traits, thinking styles, there's a high degree of perfectionism that they expect other people to demonstrate and I think they desperately want people to get it right all the time and are very intolerant of failings which is quite hard.

Another significant difficulty for the majority of participants was splitting between staff. This referred to differences of opinion and conflict between staff elicited by certain patients' behaviour. One participant acknowledged that while this was a common occurrence in a ward environment, it was intensified in eating disorders:

[ppt 7, nurse] I think that's normal but then I think it's exacerbated by the particular 
nature of the illness, the people that we're dealing with are very disturbed so obviously that splitting's going to be intensified.

\section{Physical care}

Delivering physical care included administering medication, monitoring patients' physical state, and managing weight restoration. This theme was of particular importance among nurse participants as the combination of physical and therapeutic care was a unique aspect of working in the field of eating disorders:

[ppt 1, nurse] There's the physical care alongside the mental health care that you don't get in every area of nursing. We get people with very low BMIs, so we have to monitor their physical observations... we also have people sometimes with PEG feeds or NG tubes. We have to be aware of things like what blood deficiencies cause like low potassium...and look after refeeding oedema.

Caring for patients who are physically emaciated was, at times, very difficult and shocking for some participants. Those who had worked in eating disorders longer discussed how they had become desensitised to the physical condition of very low weight patients. However, there were occasions where these participants were still shocked:

[ppt 7, nurse] I have probably got desensitised... being used to seeing people so emaciated... but I am still shocked at times... it's so emotionally and psychologically draining the intensity of that type of work that actually there has to be things that give.

Although a few participants stated feeling guilty for becoming desensitised, it was often perceived as a necessary coping mechanism that they had learnt over time. For one participant this process of desensitisation involved a shift in focus from the patient's aesthetic condition to their physical needs:

[ppt 8, nurse] That's probably some sort of psychological defence against the awfulness of the situation...the emphasis on the physical characteristics of the patient in that state become the focus so what their blood results are doing, what their heart rate is doing... they become a set of symptoms and things to monitor and measure. 
Organisational demands

Healthcare workers had multiple responsibilities involving key working with patients; formulating care plans; setting and maintaining boundaries with patients; functional duties such as supervising mealtimes; administrative duties and liaising with external bodies. For a few participants, managerial responsibilities were an additional work demand. Frequently participants reported difficulties performing responsibilities due to time constraints or limited staffing:

[ppt 2, HCSW] When there's more patients, mealtimes have to be staggered which can cause a little bit of anxiety and that is totally out of our control, because that's the amount of staff there are and the amount of patients there are.

Effective communication was considered an integral element in teamwork and the overall ward environment by all participants. Since splitting between staff was a common threat to team cohesion, effective communication was seen as crucial for counter-acting this division. Good communication was sometimes compromised by staff members' experience, lack of time, or shift rotation:

[ppt 7 , nurse] There's logistical barriers in terms of you can never capture the whole team at one time so trying to look at how you disseminate information to those people effectively, capturing nuances of what you might mean about something I think is quite complicated.

\section{Social Support}

Formal \& informal support

Formal support was highly valued by the majority of participants for providing an uninterrupted length of time in which to discuss patients and their care in depth, and reflect on their own delivery of care. One-to-one supervision was invariably considered by participants to be the most useful form of formal support. However a couple of participants reported that despite scheduling, one-to-one supervision was not implemented as often as it should be. Responses to group supervision were much more varied; some reported that group 
supervision was beneficial for team relations and communication whereas others disliked it completely. Some participants were able to identify its uses but reported that the reality did not live up to the ideal:

[ppt 5, nurse] It serves a purpose, it definitely does, it lets people get together and air some things but I don't know that it's quite all that it's supposed to be...I don't think that people address issues with each other and that the focus is always on the patients when sometimes I think the focus needs to be on the relationships between the staff and how they view the patients.

For all participants, the single-most important aspect of informal support was the immediacy of support. Being able to express feelings elicited by a patient or specific situation and seek advice from peers immediately after an incident was highly valued:

[ppt 11, nurse] You've not got to save or store anything up, and to be able to just express them at the time that you're feeling it I find is really useful for me, then I don't take it home with me. I think if I had to wait for supervision I think I'd be storing things up and I don't think that that's healthy.

Those who sought support from friends and family members reported that they could only talk vaguely or generally. This was due to the confidential nature of the work and others' lack of specific understanding about eating disorders. External support was most effective where staff had friends within the nursing profession who could relate to their experience.

\section{Job Satisfaction}

Patient-related factors

All participants reported that working with patients was the most rewarding and enjoyable aspect of their job. Some participants put more emphasis on the process of treatment including patient interaction, building therapeutic relationships, and encouraging patients to become motivated towards change:

[ppt 10, nurse] Feeling like you have connected with a patient, that you do feel that that patient trusts you, wants to talk to you, and is prepared to work with you towards the goal of 
getting them well, that has to come top of the list.

Other participants focused more on the outcome of treatment such as seeing patients recover psychologically and physically, making improvements in their quality of life, and eventually being discharged. Getting to know patients and talking to them about things other than their eating disorder was important to several participants. In these interviews, participants stated that this was key to working holistically with patients.

Although no participants identified the clinical aspect of their job as dissatisfying, all participants recognised the difficulties of working with a patient group prone to relapse and often requiring multiple hospital admissions. Several participants referred to this as 'the revolving door system', a phenomenon typical of patients across all areas of mental health. This aspect was emotionally difficult for many participants:

[ppt 3, OT] When they come back six months later and they are just emaciated, they have a BMI of eleven, that can be the biggest stab in the heart...I don't think that gets any easier. It's disheartening when you see them come back after a period of time, twice or three times even and you think 'oh god, is this what this person's life is?'... when you put in all that work... and then they come back and they've just lost it all, that's hard.

In spite of this, several participants demonstrated a certain degree of acceptance and were able to see it as part of a longer process of recovery for patients. Often participants stated that it was simply a part of their work. In some cases, it was evident that this acceptance came with more years of experience whether in eating disorders or in general psychiatry. Importantly, a couple of participants reported the need to hold on to hope for patients and approach treatment with an optimistic attitude in the face of high re-admission rates. Evidently both acceptance and hope are key to managing the negative aspects of working in eating disorders and reducing its effect on job satisfaction.

\section{Organisational factors}

In contrast, organisational factors were strongly felt by almost all participants to be the single largest source of dissatisfaction at work. Within this, time constraints and the amount of 
administrative paperwork were the most commonly reported sources of dissatisfaction. Paperwork was often seen to be excessive, unrealistic to complete and unnecessary, detracting from time working with directly patients:

[ppt 7, nurse] The expectations of in terms of paperwork, documentation, policy, all the red tape is just, if you were to do that all as you should be, you'd never see a patient, so it is that constant frustration of knowing that that side has to be taken care of but actually I just don't know the purpose of it a lot of the time.

Other important sources included staffing resources, poor team communication, shiftwork, financial considerations of providing an inpatient treatment service, and limited opportunities for non-ward-based therapeutic activities. Staff capacity was said to impinge on time, however those that identified this as a problem acknowledged that this was mostly due to sickness-related absence rather than allocation of staff. Although in general, team relations were reported to be very good, especially in terms of support, several participants reported that at times poor team communication could be dissatisfying. Only half of participants who reported ineffective teamwork as dissatisfying believed it to be a result of time constraints; some stated that poor communication within the team was distinct from a lack of time to liaise with colleagues.

[ppt 10, nurse] I struggle with that where it feels like the team's just not connecting very well... I came home from work last week feeling really fed up and I think it was definitely team issues.

Shift-work was reported by some as dissatisfying for reasons including the lack of routine, impact on personal life, and its effect on participants' emotional and physical wellbeing. For one participant, this was especially true of night shifts:

[ppt 1, nurse] I absolutely hate night shifts. They're difficult during it, they take you a long time to get over. They make you feel terrible physically and emotionally. And they're just a real struggle. You never get into a proper routine.

Despite the frustration caused by organisational factors, many of these were reported 
with a certain degree of acceptance and resignation. They were often attributed to working within the National Health Service (NHS) and were seen to be representative across all areas of healthcare regardless of speciality. Most participants saw little opportunity to address these issues and so they tended to be seen as an unavoidable aspect of being employed by the NHS:

[ppt 3, OT] Obviously staff capacity is a big issue but I don't think it'll ever change because that's just the NHS.

\section{Discussion}

This study identified work demands experienced by healthcare workers from an adult inpatient eating disorders ward. It also explored staff perspectives of social support and job satisfaction. Work demands were attributed to one of three categories - therapeutic care, physical care, and organisational demands. Within the therapeutic care category the complexities of dealing with patients' ambivalence to change and the role of splitting were particularly mentioned. Consistent with previous findings, this study found that healthcare workers faced difficulties in managing patients' ambivalence and attitudes towards treatment which in turn, complicated efforts to build therapeutic relationships (Reid et al., 2010 Wright, 2010)., Working with ambivalent patients is never easy and can become very frustrating. In the field of eating disorders, as with patients with drug and alcohol problems, motivational enhancement interventions have become very successful in helping patients to evaluate their ambivalence and increase their motivation to change (Vitousek, Watson and Wilson, 1998). To help staff overcome these barriers to engaging patients in treatment, training could incorporate principles of motivational enhancement by which specifically target ambivalence.

From the interviews, it was evident that splitting between staff and poor communication presented a threat to teamwork. Splitting has been described in the eating disorders literature for many years and it is, at times, difficult to avoid. However, it needs to be well managed as it can precipitate conflict within the team, which can cause significant stress among healthcare 
workers (Taylor et al., 1999; Tyler \& Cushway, 1995). The best way to manage splitting within a closed unit is through effective group supervision where counter-transference reactions can be usefully examined and discussed (Fagin, 2004).

Within the psychical care category, the study also found that caring for severely underweight patients was difficult in terms of coping with patients' extreme physical appearance. Given that most healthcare workers employed in mental health are primarily trained in psychiatry with a limited training in physical health, caring for patients with severe physical complications is understandably challenging. This could be addressed by regular training of staff working in eating disorders services in the management of physical complications, and by regular supervision from medically trained staff.

Finally, within the organisational demands category, the study identifies time constraints and insufficient staffing as a particular obstacle for good quality of care and as a source of job dissatisfaction, which confirms previous findings from NHS units (Prosser et al., 1997; Reid et al., 2010). The ill-fit between resources and demands in healthcare work is well established in the literature (Taylor et al., 1999; McNeese-Smith, 1999; Aiken et al., 2002) and can become a cause for concern as organisational demands are significant predictors of stress in healthcare workers (Taylor et al., 1999; Tyler \& Cushway, 1995) and high patient-tostaff ratios are linked to job-related burnout, dissatisfaction at work and intention to leave current employment (Aiken et al., 2002). It, therefore, important for that healthcare workers have a system that allows them to feedback organisational issues, such as a time constraints, to the management team, particularly where stress surrounding meal supervisions or cancelations of supervision are due to a lack of time. Organisational demands and the effect in patient care is an issue that has been recognised more widely across healthcare services and the NHS is currently implementing the initiative "The Productive Ward: Releasing Time to Care". This initiative has been developed to improve ward safety and efficiency and thereby increase the amount of time healthcare workers are able to devote to direct patient care (2011). Pilot studies have shown promising results and 
staff from these trials report feeling more empowered (NHS Institute for Innovation and Improvement, 2011). Considering the findings of this study, eating disorders wards stand to benefit from such programmes, if successfully implemented.

The study also aimed at exploring the views of healthcare workers regarding social support. All healthcare workers reported feeling generally well supported and that support at work was accessible and readily available. This is highly important as a lack of social support from either supervisors or co-workers has been associated with emotional exhaustion, depersonalisation, diminished personal accomplishment and burnout (Schaufeli, 2003). Both formal and informal support provided staff with opportunities to seek professional advice, to explore patient-staff relationships and to ventilate feelings. Formal support in the form of planned supervisions, which was usually weekly, was occasionally not as well implemented as informal support; for one-to-one supervision scheduling seemed to be problematic at times and for group supervision, the aim was not always clear. These issues could perhaps be resolved by clear guidelines for supervisors. On the other hand, informal ad hoc support was reported to be working very well; staff appreciated the opportunity to discuss patients as and when they needed. Individual supervision is essential in discussing feelings that patients can transfer to staff, particularly as a key role of healthcare workers is to re-feed the patient and that feeding is usually associated with the mother/child interaction. If these feelings are not well managed, this potentially could result in staff colluding with patients as often happens with carers of eating disordered patients (Monteleone, Treasure, Santonastaso, Favaro \& Brambilla, 2005). Group supervision, however, is equally important to help avoid splitting known to occur in eating disorders units.

And finally, the study also explored the overall job satisfaction of the participants and found that despite challenges specific to this patient group, job satisfaction came primarily from patient-related factors. This supports existing findings across caring occupations (Prosser et al., 1997; McNeese-Smith, 1999). Caring work is naturally patient-orientated (Awty 
et al., 2010) and noted for being poorly paid and having long, irregular hours (Fox \& Abrahamson, 2009; Parikh et al., 2004) therefore it is not surprising that healthcare workers found intrinsic factors such as patient interaction and building relationships most rewarding. Sources of job dissatisfaction were invariably organisational factors; no participants reported clinical aspects as dissatisfying. As previously reported, time spent working directly with patients is compromised by the administrative workload for healthcare workers (Gerolamo, 2009), undermining job satisfaction derived from patient interaction.

Although this research yields some important findings, it has some limitations. Due to time constraints, this study only collected data from one NHS eating disorders site and therefore the generalisability of results cannot be determined, this could affect particularly at the results related to organisational issues as the therapeutic relationship between eating disorders patients and the staff can be easily generalisable to other eating disorders units, as they manage very similar patients. This service primarily treated patients with anorexia nervosa which may have had a significant bearing on the type of work demands experienced by staff. Considering that the ward followed a specific treatment programme and that some work demands identified were related to team dynamics, this ward may differ from other eating disorder in-patient settings. Future research would benefit from comparing data across multiple eating disorders services. In terms of sample characteristics, all participants were White British. This was not an ethnically representative profile of ward staff, again limiting the representativeness of findings. This can be avoided in future research by using stratified sampling as opposed to the convenience sampling method used in this study. Although only two participants were male, nursing is well known as a female-dominated occupation (Evans, 1997) and therefore this was not considered unusual. Recruiting twelve participants from a fifteen-bed inpatient ward may be regarded as a good response rate, however it is possible that those who declined to participate may have chosen so due to negative work experiences; apathy towards work; or inconvenience or objection to the nature, location or time of the study. 
Conclusion

Healthcare workers face unique challenges in providing both physical and therapeutic care to eating disordered patients. Specific training aiming at reducing patients ambivalence, and at educating healthcare staff in the physical complication of this type of patients plus different formats of social support within the workplace, including planned individual and group supervision and ad hoc support, are vital in managing patients with such complex needs. In spite of the reality and difficulties of caring for patients who are often emaciated and ambivalent to treatment, the clinical environment is not a source of job dissatisfaction; rather organisational factors, which may be targeted structurally, need to be addressed to maximise job satisfaction.

\section{References}

Aiken, L. H., Clarke, S. P., Sloane, D. M., Sochalski, J. \& Silber, J. H. (2002). Hospital nurses staffing and patient mortality, nurse burnout, and job dissatisfaction. Journal of the American Medical Association, 288, 16, 1987-1993.

Arcelus, J., Mitchell, A., Wales, J. \& Nielsen, S. (2011). Mortality in eating disorders: A metaanalysis. Archives of General Psychiatry, 68, 7, 724-731.

Awty, P., Welch, A. \& Kuhn, L. (2010). A naturalistic inquiry of registered nurses' perspectives and expectations of psychodynamic therapeutic care in acute psychiatric inpatient facilities. Archives of Psychiatric Nursing, 24, 2, 104-113.

Bhadoria, R., Webb, K. \& Morgan, J. F. (2010). Treating eating disorders: a review of the evidence. Evidence Based Mental Health, 13, 1-4.

Braun, V. \& Clarke, V. (2006). Using thematic analysis in psychology. Qualitative Research in 
Psychology, 3, 2, 77-101.

Dunham-Taylor, J. (2000). Nurse executive transformational leadership found in participative organizations. Journal of Nursing Administration, 30, 5, 241-250.

Evans, J. (1997). Men in nursing: issues of gender segregation and hidden advantage. Journal of Advanced Nursing, 26, 2, 226-231.

Fagin, L. (2004). Management of personality disorders in acute in-patient settings. Part 1: borderline personality disorders. Advances in Psychiatric Treatment, 10, 93-99.

Fedorowicz, V. J., Falissard, B., Foulon, C., Dardennes, R., Divac, S. M., Guelfi, J. D. \& Rouillon, F. (2007). Factors associated with suicidal behaviors in a large French sample of inpatients with eating disorders. International Journal of Eating Disorders, 40, 7, 589-595.

Fox, R. L. \& Abrahamson, K. (2009). A critical examination of the U.S. nursing shortage: contributing factors, public policy implications. Nursing Forum, 44, 4, 235-244.

Gerolamo, A. M. (2009). An exploratory analysis of the relationship between psychiatric nurses' perceptions of workload and unit activity. Archives of Psychiatric Nursing, 23, 3, $243-250$.

Greco, P., Laschinger, H. K. S. \& Wong, C. (2006). Leader empowering behaviours, staff nurse empowerment and work engagement/burnout. Nursing Research, 19, 4, 41-56.

Hegney, D., Plank, A. \& Parker, V. (2006). Extrinsic and intrinsic work values: their impact on job satisfaction in nursing. Journal of Nursing Management, 14, 4, 271-281. 
Kaplan, A. S. \& Garfinkel, P. E. (1999). Difficulties in treating patients with eating disorders: a review of patients and clinical variables. Canadian Journal of Psychiatry, 44, 665-670.

McCann, T. V. \& Clarke, E. (2003). Grounded theory in nursing research: part 1 methodology. Nurse Researcher, 11, 2, 7-18.

McCrae, N., Prior, S., Silverman, M. \& Banerjee, S. (2007). Workplace satisfaction in a mental health service for older adults: an analysis of the effects of setting and professional status. Archives of Psychiatric Nursing, 21, 1, 17-24.

McNeese-Smith, D. K. (1999). A content analysis of staff nurse descriptions of job satisfaction and dissatisfaction. Journal of Advanced Nursing, 29, 6, 1332-1341.

Monteleone, P., Treasure, J., Santonastaso, P., Favaro, A. \& Brambilla, F. (2005). Families of people with an eating disorder. In: N. Sartorius, J. Leff, J. J. López-Ibor, M. Maj \& A. Okasha (Eds) Families and mental disorders: From burden to empowerment (pp. 113 125). New York: John Wiley \& Sons.

Morrison, R., Jones, L. \& Fuller, B. (1997). The relation between leadership style and empowerment on satisfaction of nurses. Journal of Nursing Administration, 27, 5, 27-34.

NHS Institute for Innovation and Improvement. (2011). The productive ward: releasing time to care. Retrieved May 8, 2011, from NHS Institute for Innovation and Improvement Web site: http://www.institute.nhs.uk/ quality_and_value/productivity_series/productive_ward.html 
NHS Institute for Innovation and Improvement. (2011). The productive mental health ward: releasing time to care. Retrieved May 8, 2011, from NHS Institute for Innovation and Improvement Web site: http://www.institute.

nhs.uk/quality_and_value/productivity_series/the_productive_mental_health_ward.html

Niedhammer, I., Lert, F., \& Marne, M-J. (1994). Effects of shift work on sleep among French nurses. Journal of Occupational Medicine, 36, 6, 667-674.

Parikh, P., Taukari, A., \& Bhattacharya, T. (2004). Occupational stress and coping among nurses. Journal of Health Management, 6, 2, 115-127.

Paul, T., Schroeter, K., Dahmne, B. \& Nutzinger, D. O. (2002). Self-injurious behavior in women with eating disorders. American Journal of Psychiatry, 159, 408-411.

Prosser, D., Johnson, S., Kuipers, E., Szmukler, G., Bebbington, P. \& Thornicroft, G. (1997). Perceived sources of work stress and satisfaction among hospital and community mental health staff, and their relation to mental health, burnout and job satisfaction. Journal of Psychosomatic Research, 43, 1, 51-59.

Reid, M., Williams, S. \& Burr, J. (2010). Perspectives on eating disorders and service provision: a qualitative study of healthcare professionals. European Eating Disorder Review, 18, 5, 390-398.

Schaufeli, W. B. \& Buunk, B. P. (2003). Burnout: an overview of 25 years of research and theorizing. In Schabracq, M. J., Winnubst, J. A. M. \& Cooper, C. L. (Eds.), The handbook of work \& health psychology (2 ${ }^{\text {nd }}$ ed.) (pp.383-425). West Sussex: Wiley \& Sons Ltd. 
Sharp, C. W. \& Freeman, C. P. (1993). The medical complications of anorexia nervosa. British Journal of Psychiatry, 162, 452-462.

Snell, L., Crowe, M. \& Jordan, J. (2010). Maintaining a therapeutic connection: nursing in an inpatient eating disorder unit. Journal of Clinical Nursing, 19, 3-4, 351-358.

Taylor, S., White, B. \& Muncer, S. (1999). Nurses' cognitive structural models of work-based stress. Journal of Advanced Nursing, 29, 4, 974-983.

Traynor, M., Boland, M. \& Buus, N. (2010). Professional autonomy in $21^{\text {st }}$ century healthcare: nurses' accounts of clinical decision-making. Social Science and Medicine, 71, 8, 15061512.

Tyler, P. \& Cushway, D. (1995). Stress in nurses - the effects of coping and social support. Stress Medicine, 11, 1, 243-251.

Ulrich, C., O’Donnell, P., Taylor, C., Farrar, A., Danis, M. \& Grady, C. (2007). Ethical climate, ethics stress, and the job satisfaction of nurses and social workers in the United States. Social Science and Medicine, 65, 8, 1708-1719.

Vitousek, K., Watson, S. \& Wilson, T. G. (1998). Enhancing motivation for change in treatment-resistant eating disorders. Clinical Psychology Review, 18, 4, 391-420.

Wright, K. M. (2010). Therapeutic relationship: developing a new understanding for nurses and care workers within an eating disorder unit. International Journal of Mental Health Nursing, 19, 3, 154-161. 
Table 1: Participant Characteristics

\begin{tabular}{ll}
\hline & $(\boldsymbol{n}=\mathbf{1 2})$ \\
\hline Age (years) & $38.42 \pm 8.66$ \\
Sean \pm SD & $10 / 2$ \\
Female/male & White British \\
Ethnicity & \\
Occupation & 7 \\
Nurse & 3 \\
HCSW & 2 \\
OT & \\
Working hours & 8 \\
Full-time & 4 \\
Part-time & \\
Work experience & \\
Mean \pm SD & $5.5 \pm 6.26$ \\
Years in eating disorders & \\
Years in mental health & \\
\hline
\end{tabular}


Table 2. Themes \& subthemes resulting from thematic analysis

\begin{tabular}{ll}
\hline Themes & Subthemes \\
\hline Work demands & Therapeutic care \\
& Physical care \\
& Organisational demands \\
\hline Social support & Formal and informal support \\
\hline Job satisfaction & Patient-related factors \\
& Organisational factors \\
\hline
\end{tabular}

